\title{
A REFORMA NEOLIBERAL DA EDUCAÇÃO SUPERIOR NO CHILE EM 1981
}

\section{Sebastián Donoso Díaz}

\section{Introdução}

Este artigo analisa o impacto da reforma da educação superior de 1981 no sistema universitário estadual chileno, detendo-se em um de seus principais eixos - estrutura do financiamento público -, a partir do qual são identificadas suas conseqüências mais relevantes no que diz respeito à orientação do sistema e de seus principais atores institucionais.

A temática do financiamento da educação universitária e a ação direta do Estado neste âmbito adquiriram complexidade e relevância cada vez maiores no plano internacional, o que, no caso do Chile, é bastante significativo, já que desde o final da década de 1970 as autoridades assumiram sem contrapeso "o mercado" como a polí-

Artigo recebido em dezembro/2003

Aprovado em julho/2004 tica econômica do país, incluindo todos os setores (exceto a defesa). Como conseqüencia, o Estado reduziu sua influência no setor educacional e passou a financiar a ação de setores privados como executores de suas políticas.

De outro ângulo, é significativo que mesmo depois da queda do regime militar muitos temas de interesse público não foram discutidos em esferas mais amplas da sociedade, pelo contrário são considerados conhecidos, aceitos ou rejeitados, sem uma discussão mais detida. A falta de uma busca sistemática da opinião pública, mesmo depois de treze anos de reinstaurada a democracia no país, atinge também a discussão a respeito do financiamento da educação tanto em seu nível mais técnico, como também ideológico, o que facilita manter como "verdade" muitos dos conceitos "antiestado" sustentados pelo neoliberalismo, sem que se faça uma revisão crítica de suas idéias, salvo em reduzidos círculos intelectuais. 
Este artigo pretende refletir sobre o impacto gerado pela reforma educacional de 1981 não só na estrutura de financiamento do sistema universitário, mas também, fundamentalmente, nas orientações relacionadas nessa estrutura, revisando as razões que sustentam que o Estado deva financiar suas universidades, por intermédio das quais realiza a provisão direta dos diversos serviços educativos, antecedentes que, finalmente, permitem discutir o papel do Estado nesse mercado. ${ }^{1}$

Em particular, este trabalho se reporta à esfera universitária, uma vez que, no Chile, o ensino básico e médio, diversamente do ensino superior, é obrigatório, e, portanto, o Estado deve atender a todas as demandas neste setor, inclusive empregando agentes particulares como executores, para cumprir com seu dever junto à população.

Atualmente, o sistema universitário chileno apresenta 65 instituições agrupadas em dois conjuntos que, por sua vez, implicam diferentes opções de financiamento. No Conselho de Reitores, encontram-se as instituições mais antigas e de maior tradição (16 estaduais e 9 particulares), que recebem a maior parte do financiamento estatal. As outras fazem parte do grupo chamado de "extra-conselho" - incluem as universidades privadas, criadas a partir de 1981, e que têm acesso a fundos públicos específicos.

\section{A concepção da reforma do sistema universitário chileno}

Em 1981, o regime militar realizou uma grande mudança no sistema educacional como um todo, o que também envolveu a educação universitária. O sistema universitário nacional em vigor até 1980 tinha como modelo o financiamento da oferta e previa a ação direta do Estado na educação; ${ }^{2}$ a partir de 1981, foi substituído por um modelo com componentes de financiamento da demanda.

A transformação, realizada sob um regime autoritário, foi imposta em escala nacional, sem que houvesse participação ou poder de decisão dos autores envolvidos. Naquela ocasião, o contexto político chileno distinguia-se pela falta qua- se total de participação da população nas decisões nacionais e, no plano econômico, pela implantação do modelo de livre-mercado, centrado na necessidade de introduzir doses crescentes de competitividade $^{3}$ em cada um dos setores da atividade econômica, aumentando sobremaneira a participação de setores privados, com o objetivo de diminuir a estrutura estatal e as responsabilidade do Estado na produção de bens e serviços.

Essa mudança de modelo na área educacional não se fez com base em uma discussão pública, nem em um diagnóstico que comprovasse o fracasso do modelo de subsídio e a necessidade urgente de mudá-lo. A revisão da literatura da época revela a carência de estudos que expliquem, de forma absoluta, a decisão adotada (Jofré, 1988). Em conseqüência, pode-se afirmar que a mudança na modalidade de financiamento público da educação obedeceu fundamentalmente a uma decisão política das autoridades do país em aplicar sem restrições o modelo econômico de livre-mercado em âmbito nacional, que abarcou o conjunto dos setores da sociedade, inclusive o educacional.

Essa situação foi acompanhada de uma reformulação do sistema educacional nacional, o que implicou tanto reformas estruturais, como mudanças nos mecanismos do financiamento. Das oito universidades financiadas pelo Estado formaramse 25 centros universitários. Desde então, a partir dessas oito, foram criadas novas universidades, incorporando-se, além disso, outras de origem nitidamente privada. ${ }^{4}$ Isso gerou, em pouco mais de dez anos (1981-1994), um sistema universitário estruturado sobre a base de setenta instituições, que, depois de falências, fusões e surgimento de novas corporações, se estabilizou em torno de 65 instituições. Conforme já assinalado, o Estado financia sob igual modelo seus dezesseis centros, inclusive nove universidades particulares, que fazem parte do "Conselho de Reitores".

O panorama criado pela reforma de 1981 implicou também a definição de alguns cursos "exclusivos" - primeiramente doze cursos aos quais se agregaram mais tarde outros cinco - para serem ministrados pelas universidades (DFL 1/80, Artigo no 12). Essa situação gerou, a médio prazo, 
a criação de uma nova estratificação do sistema universitário. Além disso, esse processo foi complementado desde o início pela criação de novas instâncias legais, os institutos profissionais (IP), cuja orientação é a formação de profissionais que apresentam componentes técnicos ou uma base de aplicação sólida, e os centros de formação técnica (CFT), dirigidos fundamentalmente à formação de subtécnicos.

A reforma considerou diferentes critérios de alocação do financiamento do Estado ao sistema universitário, ${ }^{5}$ fenômeno que, devido aos mecanismos empregados para a redução, por volta de 1982, de uma porcentagem significativa da contribuição do Estado, trouxe consigo outras conseqüências diretas, como, por exemplo, a vinculação do financiamento das escolas aos resultados do sistema de seleção para o ingresso nas universidades, ${ }^{6}$ - Prova de Capacitação Acadêmica (PCA) e, atualmente, Prova de Seleção Universitária (PSU). Isso gerou distorções nos critérios de admissão que até hoje não se conseguiu solucionar (Donoso, 2003).

Nesse contexto, a educação superior viu-se diante de uma nova organização estrutural, isto é, uma estratificação muito mais definida, com entidades que amparam segmentos sociais e com diversas opções de formação e de localização. Portanto, dificilmente se pode falar em um mercado homogêneo, ao contrário, trata-se de vários mercados heterogêneos, compostos por submercados, onde se relacionam e negociam diferentes forças e tensões. Assim, há um mercado elementar - os centros de formação técnica, seguidos pelos institutos profissionais, algumas universidades privadas e algumas universidades privadas e públicas -, e o mercado que comporta algumas universidades públicas e estaduais, que, por sua vez, varia segundo a localização geográfica (região ou província).

Apesar dessas mudanças de forma, é possível sustentar que a educação universitária chilena sempre existiu sob o paradigma da modernização. Desde a fundação da Universidade do Chile (meados do século XIX) até os nossos dias, não há uma mudança na concepção desse modelo. O que tem variado são os enfoques históricos dessa concepção, os quais transitaram entre os ideais de uma universidade em parte napoleônica, em parte medieval, passando pelas teorias positivistas, desenvolvimentistas, até chegar às idéias de livremercardo da atualidade.

Por essa razão é plausível perguntar se houve mudança na base dessa concepção ou se estamos em uma situação fora da modernidade. A educação universitária esteve orientada para ajustar os perfis institucionais aos novos tempos e é por isso que em certos momentos se fala em "universidade em crise" ou "educação em crise". As mudanças no sistema universitário ocorreram, basicamente, na velocidade do ajuste às demandas, ao grau de influência de suas diferentes unidades, às variações que acontecem na cultura organizacional em relação à mudança e à inovação e, ain$\mathrm{da}$, nas relações mantidas pela universidade com o sistema educacional como um todo. De outro lado - como afirma A. Gehlen -, as premissas da Ilustração caíram por terra, somente suas conseqüências permanecem (apud Habernas, 1985). Ou seja, a modernidade, como forma cultural primária, deixou de existir.

A modernidade pode ser entendida ao menos sob dois pontos de vista, a saber, no sentido filosófico e cultural, e no âmbito das leis funcionais da sociedade, da economia e do Estado, em que a ciência e a técnica passam a ser o referencial de estabilidade no contexto de um mercado onisciente, transparente e perfeito.

A modernização como concepção sustenta os processos da política educacional desde o final do primeiro quarto do século $\mathrm{XX}$ até os nossos dias. Ao longo de todos esses anos e apesar das críticas recebidas a educação universitária tem ocupado um lugar privilegiado, como uma racionalidade exemplar, mesmo quando as políticas educacionais impulsionadas pelo Estado nem sempre refletem tal relevância. Nas concepções que imperam em nossa sociedade, a universidade é, sem dúvida, um fenômeno cultural de envergadura, vinculado estreitamente ao surgimento, no século XX, de importantes setores sociais de nível médio que reconhecem na educação um papel preponderante para a obtenção de vantagens sociais, culturais e econômicas. Trata-se precisamente do referente que vem confirmar a racionalidade intrínseca ao sistema. 
O sucesso dessa concepção de maior relevância nas últimas décadas reside na reforma da educação superior, impulsionada em 1981. Isto propiciou um conjunto de condições que geraram profundas mudanças tanto na estrutura como na própria concepção da educação superior. O sistema universitário iniciou uma rápida trajetória em direção a uma nova racionalidade modernizadora, que se expressa de diferentes maneiras. Ao mesmo tempo, as mudanças incorporaram novas energias mediante o replanejamento de aspectos da vida universitária que pareciam praticamente intocáveis.

Em suma, as mudanças caracterizam-se pela passagem, em menos de uma década, de uma estrutura fechada e barroca para um mercado aberto, liberalizado, em seu mais lato sentido, e aparentemente sujeito aos controles dos mesmos agentes. Trata-se do pressuposto de que existe uma racionalidade intrínseca ao mercado que se realiza plenamente por meio deste e não pelo Estado, ou seja, é a interação livre de concepções individuais que, em seu conjunto, reflete a racionalidade do real e a realidade da razão (tudo que é racional é real; tudo que é real é racional).

Esse processo - não de todo sincronizado deixou pendentes algumas discussões decorrentes do confronto de projetos distintos em um mercado que, mesmo suportando idéias divergentes, não aceita definitivamente a geração de paradigmas alternativos. Aí reside o principal fator indicador e operador das reiteradas crises que enfrenta.

\section{Estado e mecanismos de financiamento das universidades}

O regime militar considerou desde seu início, em 1974, que o acionamento do Estado se baseava no princípio de fornecimento de subsídios, e não na visão do Estado como benfeitor. Esse aspecto, consistente com a visão de mercado projetada pela economia neoliberal (Novak, 1999), implicou a mudança do papel do Estado, de seus critérios e instrumentos de operação, elementos que serão analisados a seguir.

\section{Papel representado pelo Estado no campo} educacional

Com a reforma de 1981, a universidade deixou de ser sinônimo de educação superior, abrindo-se a uma gama de níveis e possibilidades. ${ }^{7}$ As mudanças mais notáveis podem ser observadas na desorganização do sistema - ampliação da categoria das instituições de educação superior, incremento do número de instituições em cada um dos níveis do sistema e aumento e diferenciação da oferta de cursos e de vagas.

A efetivação das propostas da reforma gerou duas novas categorias de classificação institucional: universidades "derivadas" e universidades "privadas". As primeiras constituíram-se a partir das sedes regionais que mantinham as duas universidades estaduais - Universidade do Chile e Universidade Técnica do Estado. Esse processo, alguns anos depois, também incluiu a Pontifícia Universidade Católica do Chile, que se separou de suas sedes, adquirindo autonomia e conservando o caráter de instituição pública com financiamento estadual. O segundo grupo formou-se de maneira inteiramente nova. As instituições de caráter privado não possuem financiamento direto do Estado, o que não acontece no caso das seis universidades privadas (quatro católicas e duas laicas) anteriores à reforma, as quais, paradoxalmente, mesmo sendo privadas, são identificadas com a função pública que cumprem.

Nesse contexto, podemos afirmar que o Estado passou a ser um ator secundário nesse campo, com exceção - conforme já se salientou - que ele mantém um conjunto de universidades, as quais financia parcialmente, juntamente com outras universidades privadas.

O papel passivo desempenhado pelo Estado no cenário da educação universitária deve-se, entre outros motivos, ao fato de que a legislação da reforma lhe impediu uma ação mais efetiva, ainda que pareça que ele não tenha buscado, ou não pôde conseguir, uma participação mais decisiva no setor, ${ }^{8}$ devido a problemas de financiamento adicionais que tal fato poderia implicar. Pode-se dizer que o Estado se auto-restringiu, atribuindose um papel secundário, não apenas por razões 
político-ideológicas que sustentam a reforma de 1981, mas também, e sobretudo, pela questão financeira mais direta.

\section{Instrumentos de financiamento}

Como foi esboçado, a reforma mudou os critérios de atribuição dos recursos financeiros ao sistema universitário. Até 1980, o Estado sustentava, praticamente em sua totalidade, as oito universidades do sistema, mediante a aplicação do "modelo de subsídio para a oferta", o qual se caracterizava pela provisão de montantes fixos às unidades educacionais, independentemente do total de alunos matriculados. Esse subsídio costumava ser determinado sobre a base do orçamento de anos anteriores, acrescido da correção inflacionária e dos aportes centralizados em parcelas específicas para equipamento e infra-estrutura (Donoso, Schmal, 2002).

Esse procedimento de financiamento conferia uma grande estabilidade a essas universidades, principalmente porque sua base de cálculo estava constituída por padrões históricos ajustados progressiva e marginalmente, sem gerar incertezas de curto prazo. Além disso, permitia programar atividades com prazos mais largos, independentemente da estrutura de custos, desde que não estivesse implícito mudanças bruscas e não programadas nessa estrutura. Do ponto de vista técnico, exigia um esquema de administração básico, simples e reduzido. Com efeito, não necessitava de maiores exigências operacionais, nem de informação para seu funcionamento.

Os novos instrumentos sustentam-se em um paradigma alternativo, a saber, o "financiamento da demanda", ainda que, na prática, tenham combinado ambos os modelos, resultado dos "ajustes". As mudanças (DFL No 4/1980) dividiram o aporte financeiro total basicamente em dois instrumentos - Aporte Fiscal Direto (AFD), que recebe as 25 universidades do Conselho de Reitores, e Aporte Fiscal Indireto (AFI), que recebe qualquer instituição de educação superior, de acordo com o número de alunos matriculados em meio dos 27.500 melhores pontos registrados nas provas do sistema de seleção. A lei assinala que, para melhorar a competência, deveriam ser gradualmente transferidos os fundos do AFD ao AFI, até alcançar participações equivalentes. De fato, isto não ocorreu, entre outros motivos, porque em 1982 foi congelado o orçamento para as universidades, o que, até o novo governo democrático, não se reverteu de maneira significativa (Sanfuentes, 1990).

Ademais, já existem ou são criados fundos licitáveis, seja para projetos de pesquisa - Programa Estadual de Pesquisa (Fondecyt e outros fundos setoriais) -, seja para projetos de desenvolvimento tecnológico (Fontec, Fondef), seja para outros fundos dirigidos à melhoria da qualidade (Mecesup), ${ }^{9}$ a maior parte dos quais requer algum tipo de contraparte e está, além do mais, habilitada para universidades reconhecidas pelo Estado, isto é, do Conselho de Reitores, ou, no caso das universidades privadas, "extra-conselho", que devem ter plena autonomia.

Nessa estrutura, as taxas pagas pelos estudantes (matrículas e mensalidades) transformaram-se em uma importante fonte de financiamento, chegando ao extremo de, atualmente, os preços de cursos equivalentes possuírem uma diferença menor do que as registradas há dez ou quinze anos (CSE, 2000-2003). As taxas que, antes da reforma, se diferenciavam pelo nível socioeconômico dos alunos deixaram de seguir essa condição, liberando as instituições que recebem verbas estaduais no sentido de estabelecer taxas vinculadas ao nível que consideraram apropriado. No caso dos alunos provenientes de famílias com baixos níveis de renda, gerou-se um sistema de crédito universitário ou crédito fiscal (hoje, fundo solidário) ${ }^{10}$ que contribui de maneira significativa no sistema educacional, embora, muito provavelmente, seja insuficiente, dada a demanda cada vez maior desse crédito, fruto da grande expansão da matrícula no sistema universitário, que se duplicou em menos de cinco anos e que certamente se duplicará antes do final da década - estima-se em torno de um milhão o total de estudantes para 2010 (Brunner e Elacqua, 2003).

O financiamento via AFD foi pensado como uma contribuição para o desenvolvimento de pós- 
graduação e pesquisa, tarefas que não têm razão de serem "pagas". Em contrapartida, a lógica do instrumento de financiamento via AFI reside na suposição de que para "melhorar a qualidade" de uma instituição, ela deve apresentar atrativos diferenciados. Portanto, o postulado de pontuações mais altas se orientaria para as instituições de melhor qualidade. Isso sem entrar no mérito a respeito do conceito de qualidade na educação, cuja avaliação se encontra "sob a guia da mão irreversível do mercado", argumento útil para fundamentar o inexplicável.

\section{Que razões avalizam a idéia de que o Estado deva financiar suas universidades?}

A discussão desse ponto é central para os objetivos deste trabalho. Há diversas maneiras de abordagem. A partir de uma visão econômica, por exemplo, ou a partir dos princípios sociais que regem o governo de uma sociedade democrática. Ainda que entre ambos haja elementos sinérgicos, as ênfases são diferentes.

Antes de analisá-los, contudo, é importante recapitular alguns aspectos. Primeiramente, os princípios que sustentam a mudança do papel do Estado, de "benfeitor a subsidiário", têm implicações severas na forma pela qual se organizam os instrumentos financeiros do Estado nesse campo. Em segundo lugar, essa mudança significa deixar de projetar, executar e financiar senão todas, mas grande parte das iniciativas docentes, assumindo, pois, um papel secundário, sem se comprometer, contudo, com o financiamento de instituições particulares, as quais passariam a desenvolver tarefas outrora implementadas pelo Estado. Em terceiro, isso permite questionar, no setor da educação universitária, o papel do Estado como "executor" e, portanto, se é relevante a existência de instituições públicas em pleno exercício de funções que as particulares são capazes de realizar.

Dessa forma, discutir esse tema é essencial para se compreender a política educacional, uma vez que demonstra os critérios aos quais se inclui.
O debate segundo a concepção econômica

A primeira consideração que avaliza, no caso chileno, o financiamento do Estado às universidades é de caráter histórico. Até a fundação da Universidade do Chile (1842), o que se poderia denominar "o sistema universitário nacional" era bastante incipiente. A tentativa de se criar a Universidade Pencopolitana e, depois, a Universidade de San Felipe, cujo funcionamento foi muito irregular (Labarca, 1939; Jobet, 1970; Vial, 1987), evidencia que, antes da Universidade do Chile, o movimento universitário nacional não teve nenhum incentivo. O apoio governamental foi decisivo (Serrano, 1993) para que essa universidade enfrentasse a tarefa com sucesso, o que também se estendeu à Universidade Técnica do Estado; ambas até 1981, eram públicas. Essas instituições tiveram um papel decisivo na massificação do sistema universitário chileno, já que o poder de influência das outras universidades, quando se considera o número de matrículas - exceto em parte a Universidade de Concepción -, era muito menor.

Em segundo lugar, na década de 1950, o Estado financiou de modo significativo as outras seis universidades, apesar de terem um caráter privado. Isso demonstra que, sem o apoio sistemático e relevante do Estado, dificilmente o país teria alcançado o padrão de desenvolvimento e formação de seus recursos humanos a que finalmente chegou, o que reforça o argumento de que o financiamento governamental na esfera da educação, agora estendido ao conjunto das universidades, foi fundamental.

A terceira consideração é também de índole histórica, mas apresenta condições de ordem legal. Os instrumentos legais que regularam a reforma de 1981 estabeleceram clara e expressamente os critérios de financiamento dos centros universitários que teriam ou não subsídios do Estado (Conselho de Reitores, 1981), pois até esse momento todas as universidades recebiam verbas estatais. A partir de então, as novas universidades de origem particular não mais receberiam apoio do Estado. O argumento usado foi próprio da economia de mercado, e portanto não se entende por que houve "uma mudança nas regras do 
jogo", gerando incerteza e instabilidade, ainda mais quando as normas iniciais eram de conhecimento geral, mesmo antes de serem incorporadas ao mercado.

O quarto argumento liga-se diretamente ao arcabouço econômico. O financiamento da educação pelo Estado se justificava basicamente pelos reflexos positivos numa sociedade moderna. Assim, seria vantajoso subsidiar este bem, a fim de que os indivíduos sem condições de pagar os estudos pudessem ir à escola ou aqueles que não considerassem importante o acesso à educação mudassem de opinião. Tal argumentação é válida para a análise da rentabilidade social do investimento educacional na pré-escola, no ensino fundamental e médio, mas em relação ao ensino superior há fatores mais complexos envolvidos. Chega-se ao extremo de se considerar o investimento nos níveis básicos do sistema educacional mais rentável; no entanto - muito além das especulações metodológicas sobre a forma pela qual são medidos os benefícios educativos e suas concatenações (Hanushek, 2002) - é indubitável que um país necessite de profissionais e graduados em diversas disciplinas, de forma a que o princípio geral continue sendo válido, independentemente das condições circunstanciais a esse respeito.

Uma extensão desta consideração pode ser inversamente formulada. Por que os agentes privados institucionais não investem em educação com a mesma freqüência e montante como o fazem no setor público, apesar das conseqüências externas que possam surgir a esse respeito? Certamente isso está relacionado à apropriação dos benefícios proporcionados pela educação, de forma que essa dimensão se torna relevante e deve ser considerada.

Ademais, a educação tem um papel ativo como instrumento de redução das injustiças e das diferenças sociais (privadas e públicas). Reconhecese que a educação formal tem um papel importante no que diz respeito aos incrementos da mobilidade social e, por isso mesmo, à redução das desigualdades socioeconômicas (Sapelli, 2002). Assim, o Estado procura corrigir tais diferenças subsidiando, de alguma forma, a educação em seus diferentes níveis (Donoso e Schmal, 2002a).
As desigualdades sociais são consideradas "imperfeições do mercado" e, no atual esquema dominante, tenta-se corrigir esse problema de maneira indireta, via impostos, subsídios e regulações, ou por meio de produção e fornecimento diretos do bem/serviço, que geram reflexos positivos na sociedade e benefícios sociais. No entanto, essa escolha está limitada, porque a despesa pública em um setor específico, no caso a educação, deve competir com outros setores que também demandam recursos e que também têm um impacto positivo, embora nem sempre devidamente quantificado, como saúde, habitação, seguridade social, entre outros. Além disso, a despesa pública destinada ao setor educacional deve ser partilhada - e isso implica uma competição interna ao setor - entre a educação universitária e os níveis pré-escolar, fundamental, médio, de adultos etc.

Ao analisar a distribuição dos recursos públicos às universidades, deve-se abordar, ainda, a questão da provisão do serviço educativo por meio direto (universidades estadual) ou indireto (universidades particulares).

Em termos gerais, as principais fragilidades "do mercado educacional universitário" são:

- A valorização social conferida à disponibilidade da sociedade para debater e trocar idéias e dirimir de modo civilizado os conflitos é substantivamente maior do que a particular.

- Quem passa para a educação superior já se encontra apto para se incorporar ao mercado de trabalho, e, portanto, de ter recursos que complementem a renda familiar. Mas estando na universidade, tais recursos passam a competir com gastos em função de uma eventual renda futura, fato que na prática, em muitas famílias de baixa renda, obriga a protelar a educação dos filhos.

- A indisponibilidade de um mercado de crédito de massa associado à educação superior, devido ao risco elevado causado pela incerteza acerca do término bem-sucedido dos estudos e pelas possibilidades de recuperação do crédito outorgado, dada a dificuldade de poder sustentar irrefutavelmente o emprego futuro dos que concluíram o curso. 
- Os impactos positivos no âmbito da pesquisa, particularmente no campo das ciências básicas, das ciências sociais, das ciências humanas, das artes e das letras, não apresentam resultados tão satisfatórios quanto as taxas apresentadas por outros setores. Isto é, seu custo/oportunidade é muito menor e, portanto, pode ser usufruído pela sociedade sem que isso implique uma redução do consumo, em particular.

Esses problemas resultam em um investimento privado abaixo do que a sociedade como um todo demanda, e cuja envergadura é dada pela valorização que se faz de cada uma dessas imperfeições. Vale dizer que não existem estudos que apontem para a direção de quantificar a valorização social da educação universitária, em virtude, talvez, da dificuldade de se realizar tal medição.

Esses pontos débeis do mercado reforçam a necessidade de intervenção do Estado no campo da educação, o que é expresso nos requerimentos de financiamento público de alguns centros de formação universitária, mas isso não quer dizer necessariamente um fornecimento direto do serviço educacional por parte do Estado.

A razão de ser das universidades estaduais reduziu-se a âmbitos muito específicos, obrigadas pela necessidade de competir por financiamento público e privado. De fato, em seus orçamentos, o componente público é cada vez menor em comparação ao privado. Nesse sentido, pode-se falar na "privatização" das universidades públicas, uma vez que dependem cada vez mais do setor privado. Simultaneamente, as universidades privadas aspiram a quotas cada vez maiores de financiamento público, e a lógica mercantil predominante segue nessa direção.

O espaço restrito deste artigo não permite a análise de todos os problemas que esse tema incita. Portanto, é lícito perguntar: O que justifica que alunos provenientes de famílias de baixa renda não tenham acesso ao crédito universitário se entram numa instituição de educação universitária "extra-conselho", mas o tem caso cursem uma universidade pública? Esse tema se esgota na discussão do financiamento dos estudos universitários? A universidade só é vista como a docência de pré-graduação?

\section{A partir da concepção social}

Sustentamos que a atual visão da política de financiamento da educação universitária pública no Chile está desligada, fundamentalmente, dos aspectos mais relevantes de formação de recursos humanos de nível superior, assim como das principais solicitações de apoio em matéria de estudos e investigação, sobretudo aquela associada ao desenvolvimento. ${ }^{11}$

A atual alocação de recursos financeiros para as universidades do Conselho baseia-se em uma concepção histórica de destinação de verbas. Em outras palavras, "congelou-se a realidade" em um determinado momento e, ao mesmo tempo, o considerou sob um ponto de vista tecnocrático, empregado para alocar recursos, o que de alguma forma não relaciona os mecanismos de alocação financeira com os resultados alcançados pelas escolas, ${ }^{12}$ reduzindo perigosamente a visão do tema à discussão do montante de recursos alocados ao setor universitário público, sem penetrar plenamente na sua esfera mais complexa, a saber, seu impacto na qualidade e na eqüidade da formação e do trabalho científico tecnológico (pesquisa) associado a essas escolas.

Argumenta-se a esse respeito que há necessidade de se abordar a um só tempo as melhorias de qualidade da formação e da eqüidade social e os aportes ao desenvolvimento. Entretanto, esses aspectos costumam se apresentar como sendo de igual importância, mas com escassa interdependência. Não obstante a qualidade e a eqüidade serem fenômenos diferenciáveis, eles têm sido hierarquizados de forma que os desafios reais de melhoria de qualidade (excelência) se relacionem mais com a eficiência no uso dos recursos educativos do que com seu fornecimento e sua aplicação em um campo definido do desenvolvimento que vai além da docência direta.

Assim, a qualidade de uma instituição está associada aos êxitos de seus estudantes, considerados antes um resultado individual que um êxito pessoal-social. Isso contradiz o sentido de "bem público" da educação, uma vez que enfatiza a apropriação privada dos benefícios e reduz significativamente a dimensão da eqüidade quase ao 
âmbito assistencial, distanciando-a das visões que apresentam a educação de qualidade como um direito de todo estudante.

Dessa forma, os resultados da formação universitária são explicados por esquemas dominantes "de mercado", como efeito de oscilações individuais, e não pelo fornecimento de condições adequadas para cumprir com as obrigações estudantis. Ou seja, privatizam-se tanto o êxito como o fracasso na universidade (Gentile, 1997, p. 61), muito mais do que se atribui esses resultados às políticas públicas empreendidas neste setor, sobretudo aquelas que concernem à eqüidade.

Estamos falando de princípios quando nos referimos à eqüidade - não se trata apenas de um tema que, para evitar conflitos sociais extremos, deva ser considerado.

Assumir a sociedade de mercado como "injusta" implica estabelecer critérios (políticas) destinados à sua correção. Isso vale tanto do ponto de vista econômico, como, certamente, do social. Rawls $(1995,1999)$ sustenta que as instituições sociais devem responder a um pacto ou contrato social, no qual indivíduos racionais acordam dois princípios aceitáveis por todos. O primeiro diz respeito à "liberdade" - cada pessoa tem o mesmo direito ao mais extenso sistema de liberdades básicas, distribuídas em partes iguais, compatível com um sistema similar de liberdades para todos. O segundo assume que as desigualdades econômicas e sociais devem ser estruturadas de forma a proporcionar maiores benefícios aos que têm menor poder aquisitivo. Pretende, ainda, determinar quando e em que quantidade a desigualdade pode ser justificada. Para Rawls, a desigualdade é produto da forma pela qual são distribuídos os bens sociais primários - direitos, liberdade, oportunidades, poderes, assim como renda e ativos - que permitem aos cidadãos aumentar a sua possibilidade de sucesso no sentido de concretizar seu projeto de vida.

Essa idéia contém um elemento essencial ainda que condicionado a restrições: a desigualdade tem fundamento socioético quando se emprega para beneficiar os de menor poder aquisitivo. Portanto é necessária para maximizar as expectativas dos que se encontram em pior situação na escala social. Trata-se de um caso especial do princípio de distribuição eqüitativa que prescreve a divisão igualitária dos bens primários sociais se, e somente se, existir uma distribuição alternativa que redunde em um benefício maior para os menos favorecidos. Se a sociedade dispõe de uma opção mais proveitosa para a população de baixa renda, em princípio a desigualdade estaria justificada (Rawls, 1995, p. 281).

Em conseqüência, o Estado responderia à sua vocação para reduzir a iniqüidade, dado que na atual conjuntura os menos favorecidos socialmente têm, em geral, acesso à educação de alta qualidade, contudo têm mais dificuldade para entrar na universidade (Donoso, 2003).

Nesse sentido, quando se assume que a educação é um bem público, com base nas premissas de Rawls, Fullan (1999) e Latapi (1993), compreende-se o sentido da existência de universidades públicas, já que garantem a preservação e o desenvolvimento de interesses e valores comuns, que privilegiam o benefício da maioria, em especial dos mais desfavorecidos. O Estado, portanto, valida a educação como um bem de fornecimento público; em contrapartida, quando se trata de instituições particulares, em razão da diversidade, a visão em relação à educação é outra, o que não deixa de ser legítimo. ${ }^{13}$ Dessa forma, pode-se falar em coexistência de ambos os fornecimentos do serviço educativo somente se o sistema público permitir o acesso de todos os cidadãos.

Quando se tem em mente a pesquisa e seu aporte ao desenvolvimento, levando em conta que os impactos sociais positivos do tornar-se universitário não são de todo relevantes para as instituições particulares, daí seu interesse reduzido em apoiar "a pesquisa nesse âmbito", é mais forte ainda a necessidade de estudar os problemas que afetam os mais desfavorecidos (e os mecanismos de correção das desigualdades sociais), uma vez que o interesse dos particulares não se associa à rentabilidade social dessas tarefas. Isso reforça sobremaneira a importância de que o Estado, como executor, tenha uma participação direta neste âmbito, inclusive como um princípio que salvaguarde a diversidade social. 
Aqui, a visão social está relacionada à concepção econômica, marcando o conjunto de desafios associados aos efeitos das políticas públicas. Conforme vimos, o tema da qualidade da educação é tributário da idéia de eqüidade, explícita ou implicitamente, e esta com a visão de justiça. Ademais, os resultados de desempenho escolar associam-se fortemente aos níveis socioeconômicos e culturais da população (capital social e cultural), aspecto que pode travar ou potencializar, segundo o caso, os efeitos da intervenção educacional (Brunner e Elacqua, 2003).

Assim, para construir uma sociedade mais justa e combater a força regressiva das variáveis socioculturais nos grupos mais vulneráveis, são requeridas estratégias que combinem fatores que incidam sobre a eqüidade socil ecultural. O excessivo otimismo sobre o papel da educação como elemento-chave do desenvolvimento, próprio dos anos de 1960, cedeu espaço para visões mais realistas acerca das possibilidades efetivas de se "romper" com o círculo da pobreza via educação, no sentido de reduzir a distância entre capital social, cultural, econômico e educacional entre os diversos grupos sociais, por meio de políticas públicas direcionadas a essa finalidade (Sen, 2000).

Tais políticas, por sua vez, devem estar inseridas em uma estratégia geral que contemple a superação de desequilíbrio estrutural de nossa sociedade entre produção e reprodução de desigualdades econômicas e sociais, lato sensu, e aquelas provenientes do desenvolvimento da cultura democrática centrada em valores universais de eqüidade, justiça social e cidadania, para o qual se requer uma reestruturação dessas políticas.

Os desafios acerca da elaboração de políticas públicas no campo educacional de nível superior residem na importância de se alcançar um consenso básico sobre o tipo de educação necessária e quais são as estratégias requeridas para sua implantação. Ou seja, uma política específica de financiamento que contemple a revalorização e a compreensão da educação em função de benefícios que reporta como bem público; vale lembrar a relevância nesse processo do enfoque à pesquisa e à formação educacional.

\section{Financiamento e mecanismo das universidades públicas: um tema em aberto}

O profundo impacto da reforma da educação superior de 1981 no sistema universitário estatal chileno não pode ser restrito a uma discussão técnica dos processos envolvidos no financiamento público. A reforma implicou uma transformação radical acerca do papel social dos centros estatais e públicos não só porque introduziu a lógica econômica de livre-mercado, mas também porque o Estado assumiu um papel passivo, apoiado em parte por uma legislação deficiente. Além disso, as escolas e as autoridades do país não discutiram a lógica imposta; não existem parâmetros consensuais de avaliação, ajustam-se as variáveis ao modelo fixado segundo o grau de sucesso alcançado.

Entretanto, em uma perspectiva de longo prazo, o mercado não é um aliado eficiente. Os prazos exíguos que lhe são peculiar, os desajustes elementares que censura e o alto custo que representa para as pessoas a desigualdade de informação denotam uma estrutura complexa que requer um agente avaliador, neste caso o Estado, que salvaguarde os interesses comuns e particulares.

A visão neoliberal do Estado reduziu o mecanismo de suas instituições a uma situação que atenta contra a eqüidade. Alguns centros universitários do Estado, no desespero de compreender as leis do mercado, esqueceram suas raízes históricosociais. É preciso, pois, recuperar os espaços públicos de debate e análise dos problemas sociais.

Dessa forma, há fortes razões para que, de um lado, o Estado tenha suas próprias universidades e as financie devidamente e, de outro, que estas forneçam serviços educativos de bom nível no que concerne à graduação, à pós-graduação, à pesquisa, à extensão e à assistência no nível técnico.

Assumir esta visão é compreender que a "máxima paretiana" de implementar medidas que beneficiem a todos, sem no entanto postergar alguém, é um argumento impossível de se cumprir e, não apenas isso, é a própria camisa de força do Estado, quando considerado um ideal. De outro lado, é evidente que "o custo de conveniência" princípio-chave de economia - também não po- 
derá ser cumprido. Por isso mesmo, a ação do Estado requer razões fundamentadas em princípios que ultrapassem uma concepção meramente econômica e assumam critérios societários - vérticeschave da discussão aqui empreendida.

\section{NOTAS}

1 Até 1980, falar no Chile de sistema universitário e sistema de educação superior era a mesma coisa. A partir de 1981, o sistema de educação superior envolveu universidades, institutos profissionais e centros de formação técnica.

2 Esta situação envolveu todo o sistema educacional, incluindo a educação primária e secundária.

3 A reforma, segundo foi anunciado ao público, tinha como premissa a necessidade de introduzir elementos de competitividade na educação universitária, alinhada com políticas similares na educação básica e média. Por esta via, pretendia-se incrementar níveis de eficiência nesse campo, mas não se especificou de forma ampla os indicadores de eficiência empregados.

4 No início, foram criadas universidades e institutos profissionais do Estado, entretanto logo a pressão de alguns grupos sociais de comunidades regionais fez com que entidades de menor porte se tornassem igualmente universidades.

5 Incorporou-se aí a decisão de diminuir progressivamente a contribuição estatal até alcançar 50\% do que o Estado fornecia em 1980.

6 No Chile, existe um sistema único de avaliação dos candidatos às vagas universitárias do Conselho, baseado em um conjunto de três provas obrigatórias, prestadas simultaneamente uma vez ao ano.

7 A Lei Orgânica Constitucional de Ensino, de 9 de março de 1990, define como instituições de ensino superior universidades, academias superiores das Forças Armadas, Carabineiros e Investigações, institutos profissionais e centros de formação técnica.

8 Como agente financiador de uma fração do sistema universitário, o Estado renunciou a ter um papel ativo em relação à possibilidade de dar orien- tações concretas acerca das prioridades requeridas pelo bem comum da sociedade, apoiando ou estimulando programas que, não obstante serem objeto de pouca demanda no mercado, são relevantes para o desenvolvimento do país e da sociedade.

9 Crédito conferido pelo Banco Mundial para este fim.

10 Sistema caracterizado por ser de baixo interesse, ao qual se resignam os alunos que comprovem não possuir recursos econômicos suficientes. Inicialmente, o fundo teria um aporte do Estado, porém depois deveria se auto-sustentar. Entretanto, 22 anos após sua implementação, isso ainda não ocorreu.

11 Isso implica também em reconhecer que não há um único projeto-país e tampouco se dispõe de uma política de Estado nessa área que tenha a ver com a formação de técnicos, profissionais, pós-graduados, nem com o desenvolvimento científico tecnológico mais além da "excelência". Ou seja, não existem fundos temáticos relevantes nesse campo.

12 Isso compreende a necessidade de se dispor de indicadores ajustados às suas linhas de base e não somente aos padrões de desempenho final.

13 O mesmo processo de globalização mostra que o Estado é a única instituição capaz de "defender" os valores e os interesses dos diversos grupos sociais, sobretudo os mais desfavorecidos, argumento que também segue a lógica de Rawls. Quando o Estado se esquiva dessa tarefa, a sociedade fica indefesa, o que abre espaço a explosões político-sociais.

\section{BIBLIOGRAFIA}

BRUNNER, José J. (1993), "La Reforma de 1980 diez años después”. Foro de la Educación Superior. Santiago do Chile, Corporación de Estudios Universitarios, pp. 229-238.

BRUNNER, José J. \& ELACQUA, Gregory. (2003), Capital humano en Chile. Santiago do Chile, Universidad Adolfo Ibáñez.

CONSEJO de Rectores. (1981), Nueva legislación universitaria chilena. Santiago do Chile, Consejo de Rectores. 
CONSEJO Superior de Educación. (2000, 2001, 2002, 2003), Indices: información sobre el sistema de educación superior chileno. Santiago do Chile, Consejo Superior de Educación.

DONOSO, Sebastián. (2003), Éxito y fracaso en el proceso de selección a las universidades del Concejo de Rectores: variables asociadas al fenómeno. Santiago do Chile, Universidad Academia de Humanismo Cristiano - PIIE.

DONOSO, Sebastián \& SCHMAL, Rodolfo. (2002), "Elementos para definir una política de financiamiento de la educación pública". Pensamiento Educativo, 31: 256282.

. (2002a), "El financiamiento de la educación pública en Chile: una proposición de cambio". Paideia, 32: 167-202.

FULLAN, M. (1999), The change forces: the sequel. Londres, Folmer Press.

GENTILI, P. (1997), "El consenso de Washington y la crisis de la educación en América Latina". Archipiélago: Cuadernos de Crítica de la Cultura, 29: 56-65, Bacerlona.

JOBET, Julio César. (1970), Doctrina y praxis de la educación en Chile. Santiago do Chile, Editorial Universitaria.

JOFRÉ, G. (1988), "Subvenciones en educación". Estudios Públicos, 32: 31-55.

HABERMAS, Jürgen. (1985), El discurso filosófico de la modernidad. Madrid, Taurus (ed. espanhola, 1993).

. (1987), Teoría de la acción comunicativa. Madrid, Taurus, 2 vols.

HANUSEHEK, E. (2002). "Publicity provided education". Working Paper Series, 8799, Cambridge, NBER.

LABARCA, Amanda. (1939), Historia de la educación en Chile. Santiago do Chile, Editorial Universitaria.
LATAPÍ, P. (1993), "Reflexiones sobre la justicia en educación". Revista Latinoamericana de Estudios Educativos, XXIII (2): 9-41.

MORIN, Edgar. (1986), El método: el conocimiento del conocimiento. Madrid, Ediciones Cátedra (ed. espanhola, 1988).

NOVAK, Michel. (1999), "La crisis de la socialdemocracia". Estudios Públicos, 74: 5-32.

RAWLS, J. (1995), Teoría de la justicia. México, Fondo de Cultura Económica. . (1999), Justicia como equidad. 2 ed. Madrid, Tecnos.

SANFUENTES, Andrés. (1990), Políticas económicas para la universidad. Santiago do Chile, Programa de Postgrado en Economía - Ilades, Georgetown University.

SAPELLI, Claudio. (2002), "La economía de la educación y el sistema educativo chileno". Cuadernos de Economia, Latin American Journal of Economics, 39 (118): 281-296.

SEN, Amartya. (2001), Desarrollo y libertad. Madrid, Planeta.

SERRANO, S. (1994), Universidad y nación. Santiago do Chile, Editorial Universitaria.

VIAL, Gonzalo. (1987), Historia de Chile (vol. I: La sociedad chilena en el cambio de siglo [1891- 1920]). Santiago do Chile, Santillana. 


\section{A REFORMA NEOLIBERAL DA EDUCAÇÃO SUPERIOR NO CHILE EM 1981}

Sebastián Donoso Díaz

\section{Palavras-chave}

Financiamento público da educação; Orientação universitária; Universidades estaduais; Neoliberalismo; Educação superior chilena.

Este artigo analisa as principais orientações da reforma universitária chilena de 1981. Discutimos o impacto sofrido pelo sistema público de educação universitária e, particularmente, o papel que o Estado passou a assumir neste campo após a aplicação de eficientes instrumentos financeiros condizentes com a política de livre-mercado. Defendemos neste trabalho uma política de financiamento dos centros governamentais que seja consistente com um papel mais ativo do Estado e que vislumbre uma sociedade mais justa. Analisamos fatores essenciais na esfera da educação que foram sendo esquecidos na ânsia por funcionar, com eficiência, sob as leis do mercado.

\section{THE NEOLIBERAL REFORM OF COLLEGE EDUCATION IN CHILE IN 1981}

\author{
Sebastián Donoso Díaz
}

\section{Keywords}

Public financing of education; College orientation; State universities; Neoliberalism; Chilean college education.

This article analyses the main orientations in the Chilean college reform in 1981. We discuss the impact on the college education public system and, particularly, the role that the State has taken on in the field after applying efficient financial instruments in agreement with free-market policies. In the paper we support a policy of consistent governmental financing with a more active role of the State that foresees a fairer society. We also analyze essential factors in education that have been forgotten in the eagerness of making it work more efficiently under market laws.

\section{LA RÉFORME NÉOLIBÉRALE DE L'ÉDUCATION SUPÉRIEU- RE AU CHILI EN 1981}

\author{
Sebastián Donoso Díaz
}

\section{Mots-clés}

Financement public de l'éducation; Orientation universitaire; Universités d'État; Néolibéralisme; Éducation supérieure au Chili.

Cet article analyse les principales orientations de la réforme universitaire chilienne de 1981. Il aborde l'impact souffert par le système public de l'éducation universitaire et, particulièrement, le rôle que l'État passe à exercer dans ce domaine suite à l'application d'instruments financiers efficaces, appropriés à la politique de la libre concurrence. L'auteur défend, dans ce travail, une politique de financement des centres gouvernementaux qui va de pair avec un rôle plus actif de l'État et qui ait en vue une société plus juste. Il analyse les facteurs essentiels dans la sphère de l'éducation qui ont, suite à la volonté pressante de fonctionner avec efficacité sous les lois du marché, peu à peu été oubliés. 